\title{
Molecular Cloning of the Pyruvate Dehydrogenase Complex Genes of Escherichia coli
}

\author{
By JOHN R. GUEST* AND PAUL E. STEPHENS \\ Department of Microbiology, University of Sheffield, Sheffield S10 2TN
}

(Received 19 May 1980)

\begin{abstract}
The three components of the pyruvate dehydrogenase complex of Escherichia coli are encoded by three linked genes, ace $E$ (pyruvate dehydrogenase, E1), ace $F$ (dihydrolipoamide acetyltransferase, E2) and lpd (lipoamide dehydrogenase, E3), situated close to the nadC (quinolinate phosphoribosyltransferase) and aroP (general aromatic amino acid permease) genes with the gene order: nadC-aroP-aceE-aceF-lpd. Several types of transducing phages, $\lambda$ nadC and $\lambda l p d$, carrying the nadC and $l p d$ genes were isolated from populations of artificially constructed transducing phages containing R.HindIII or R.EcoRI fragments of bacterial DNA, by selecting for their ability to complement the metabolic lesions of the corresponding mutants. The cloned fragments were extended to include a functional ace operon by in vivo methods involving prophage insertion into the nadC-lpd region and aberrant excision to yield $\lambda$ nadC-lpd and $\lambda l p d$-ace phages. These contained overlapping segments of bacterial DNA capable of expressing the $a c e E$, ace $F$ and $l p d$ genes. A physical map of a 20 kilobase pairs $(\mathrm{kb})$ segment of bacterial DNA encoding the entire nadC-lpd region, bounded by R.HindIII and R.EcoRI targets and possessing several internal restriction targets, R.HindIII (3) and R.EcoRI (2), was constructed. Using a combination of nutritional and enzymological studies with dilysogens and genetic analysis with ace mutants the approximate positions of the genes specifying the pyruvate dehydrogenase complex were traced to a $9.5 \mathrm{~kb}$ segment of the restriction map. The cloned lpd gene was expressed in the complete absence of a functional ace operon and when the major $\lambda$ promoters were repressed. This confirms that the $l p d$ gene can be independently transcribed from its own promoter.
\end{abstract}

\section{INTRODUCTION}

The pyruvate dehydrogenase complex of Escherichia coli catalyses the overall conversion of pyruvate to acetyl-CoA

$$
\text { Pyruvate }+\mathrm{NAD}^{+}+\mathrm{CoASH} \rightarrow \text { Acetyl-SCoA }+\mathrm{CO}_{2}+\mathrm{NADH}+\mathrm{H}^{+}
$$

through a series of enzyme-bound intermediates (Reed, 1974; Guest, 1978). It is a very large complex containing multiple copies of three different enzymic components: pyruvate dehydrogenase or decarboxylase (E1), dihydrolipoamide acetyltransferase (E2) and lipoamide dehydrogenase (E3). The molecular weights have been estimated as 96000 to 100000 (E1), 70000 to 89000 (E2) and 56500 (E3) for the individual chains and up to $6 \cdot 1 \times 10^{6}$ for the complex (Eley et al., 1972; Vogel \& Henning, 1971; Vogel et al., 1971; Gebhardt et al., 1978; Vogel, 1977; Danson et al., 1979). There appears to be a disproportionate content of enzymic components in the native complex but the polypeptide stoicheiometry, if constant, is still controversial. The structural genes, $a c e E$ and $a c e F$, for the dehydrogenase and acetyltransferase components constitute an operon with $a c e \overrightarrow{E F}$ polarity, very close to the nadC (quinolinate phosphoribosyltransferase) and aroP (general aromatic amino acid permease) genes at 2.6 min in the E. coli linkage map (Langley \& Guest, 1977, 1978; Bachmann \& Low, 
1980). The lipoamide dehydrogenase structural gene, $l p d$, is linked to the ace genes thus: nadC-aroP-aceE-aceF-lpd (Guest, 1974). The amount of DNA required to code for single copies of each polypeptide component approximates to 6.5 kilobase pairs $(\mathrm{kb})$ and this is consistent with the size of the aceE-lpd region that can be deduced from P1 cotransduction frequencies (Guest, 1974). The specific dehydrogenase (E1) and dihydrolipoamide succinyltransferase (E2) components of the analogous 2-oxoglutarate dehydrogenase are encoded by the $s u c A$ and $s u c B$ structural genes, which constitute an operon with the same functional polarity $(\operatorname{suc} \overrightarrow{A B})$ at $16.4 \mathrm{~min}$ in the $E$. coli linkage map (Guest, 1978). The lipoamide dehydrogenase component of the 2-oxoglutarate dehydrogenase complex is encoded by the same ace-linked lpd gene and this poses the problem of how the expression of a single $l p d$ gene is controlled and geared to the expression of the ace and suc operons. Biochemical studies with polar and deletion mutants indicate that the ace, suc and lpd genes are independently regulated, although expression of the $l p d$ gene is normally coupled to the synthesis of both complexes (Langley \& Guest, 1977, 1978). This suggests that the lpd gene has its own promoter and regulatory elements and, in consequence, need not be expressed with the same polarity as the closely linked ace genes. An autoregulatory mechanism based on the dehydrogenase (E1) and uncomplexed lipoamide dehydrogenase (E3) components functioning as negatively acting repressors at the corresponding operator sites has been proposed (Guest, 1978). Other outstanding problems associated with the two complexes include: the biochemical basis for the reaction specificities of the components, the subunit interactions involved in the assembly of each complex and the evolutionary relationships between the corresponding E1 and E2 components and between different regions of the dihydrolipoamide acetyltransferase chain. The emergence of in vitro recombination methods and DNA-sequencing techniques offers new approaches for their investigation as well as opportunities for the rapid solution of some of these problems. With this aim in view the cloning of the genes encoding the pyruvate dehydrogenase complex of $E$. coli in lambda vectors, using a combination of in vivo and in vitro methods, is reported.

\section{METHODS}

Bacterial strains. The characteristics and sources of the strains of Escherichia coli are listed in Table 1. Most of these have been described previously: ace mutants and deletion strains by Langley \& Guest (1977) and $l p d$ mutants by Guest \& Creaghan (1973). The parental strains H, K1-1 and W1485E were used as controls in the enzymological studies.

Bacteriophages. The characteristics of the three vector phages are shown in Fig. 1. Phage NM540 (srI $I \lambda$ $1-2_{\Delta} \operatorname{shn} \lambda 3^{+} a t t^{+} i m m^{21} \operatorname{nin} 5 \operatorname{shn} \lambda 6^{\circ}$ ) is an insertion vector for R.HindIII (Borck et al., 1976). Phage

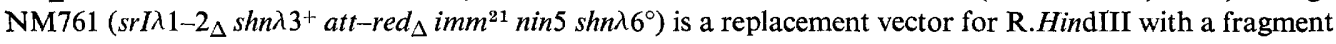
of E.coli DNA containing the $\operatorname{supF}$ gene inserted at the $\operatorname{shn} \lambda 3$ site; it is a derivative of NM742 (Murray et al., 1977). Phage NM781 ( $\operatorname{sr} I \lambda 1-3_{\Delta}$ cI857 nin5) is a replacement vector for R.EcoRI with a supE-containing fragment inserted between $s r I \lambda 1$ and $s r I \lambda 3$ (Murray et al., 1977). Pools of recombinant phages containing the corresponding restriction fragments of $E$. coli CR63 DNA were kindly provided by Dr N. E. Murray. Other phages - $\lambda \mathrm{imm}^{434}, \lambda \mathrm{imm}^{21}, \lambda$ bio 1 (int-red $\left.\mathrm{imm}^{21}\right), \lambda b 2 \mathrm{cimm^{21 }}, \lambda b 2 \mathrm{cimm} \mathrm{im}^{\lambda}$ and $\lambda v i r$ - were used as heteroimmune helper phages, for curing and routine tests for immunity and phage-sensitivity.

Media and general methods. The rich medium was L broth (Lennox, 1955) with glucose $(0 \cdot 1 \%$, w/v) for routine subculture of ace and $l p d$ mutants but without glucose for other organisms and for the preparation of phage stocks. Phage assays were made on BBL medium containing $\left(\mathrm{g}^{-1}\right)$ : $\mathrm{BBL}$ Trypticase, $10 ; \mathrm{NaCl}, 5$; Difco Bacto agar, 10 for plates and $6 \cdot 5$ for top layers.

The minimal media $(E)$ with carbon sources $D$-glucose $(10 \mathrm{~mm})$, potassium acetate $(50 \mathrm{~mm})$ or potassium succinate $(50 \mathrm{mM})$ used for nutritional tests and genetic selections have been described previously (Langley \& Guest, 1977). Supplements were added as required: acetate ( $2 \mathrm{~mm}$ with glucose as substrate, or $4 \mathrm{~mm}$ with succinate), succinate $(2 \mathrm{mM})$, L-amino acids $\left(30 \mu \mathrm{g} \mathrm{ml}^{-1}\right)$, thymine $\left(50 \mu \mathrm{g} \mathrm{ml}^{-1}\right)$, vitamins $\left(10 \mu \mathrm{g} \mathrm{ml}^{-1}\right)$. Selective media were sometimes enriched with Difco Bacto nutrient broth $(0 \cdot 2 \%, \mathrm{v} / \mathrm{v})$ or Difco Casamino acids (vitamin-free; $0 \cdot 2 \mathrm{~g}^{-1}$ ).

The general methods of Borck et al. (1977) were used for the preparation of phage stocks, phage assays and other routine procedures. The nutritional characterization of mutants and their derivatives have been described previously, as have the methods for testing resistance to azide and aromatic amino acid analogues 


\section{Table 1. Strains of Escherichia coli K12}

\begin{tabular}{|c|c|c|}
\hline Strain & Relevant genotype & Source \\
\hline $\mathbf{H}$ & thi azi relA? (Hfr) & W. Hayes \\
\hline K1-1 & met $B$ rel $A$ thy $A$ tsx pps azi ton? & H. L. Kornberg \\
\hline W1485E & sup E iclR & C. Yanofsky \\
\hline $\mathrm{C} 600$ & thr leu thi sup E tonA & N. E. Murray \\
\hline C600(P2) & thr leu thi supE tonA $(\mathrm{P} 2)$ & P2 lysogen of $\mathrm{C} 600$ \\
\hline CR63 & $\sup D \lambda^{\mathbf{R}}$ & N. E. Murray \\
\hline KS302 & $(\text { gal-bio })_{\Delta}$ & K. Shimada \\
\hline T94A & mutT1 bio-1 phe-1 $(\lambda)$ & K. A. Stacey \\
\hline JRG73 & aceE1 & Formerly W1485A1 \\
\hline JRG260 & aceE131 & Formerly WGAaceE131 \\
\hline JRG354 & $l p d-7$ & Formerly Hlpd7 \\
\hline JRG355 & $l p d-8$ & Formerly Hlpd8 \\
\hline JRG582 & $(\operatorname{nad} C-\operatorname{aroP}) \Delta 2$ & Formerly $\mathrm{H} \Delta 2$ \\
\hline JRG590 & $($ nadC-aceF $) \Delta 10$ & Formerly $\mathrm{H} \Delta \mathrm{10}$ \\
\hline JRG593 & $($ aroP-ace $E) \Delta 13$ & Formerly $\mathrm{H} \Delta 13$ \\
\hline JRG599 & $($ aroP-lpd $) \Delta 18$ & Formerly $\mathrm{K} \Delta 18$ \\
\hline JRG603 & $($ nadC-ace E $) \Delta 22$ & Formerly $\mathrm{K} \Delta 22$ \\
\hline JRG613 & $($ nadC-aceE $) \Delta 32$ & Formerly $\mathrm{K} \Delta 32$ \\
\hline JRG615 & $($ nadC-aceE $) \Delta 34$ & Formerly $\mathrm{K} \Delta 34$ \\
\hline JRG616 & $($ nadC-aceE) $\Delta 35$ & Formerly $C \Delta 35$ \\
\hline JRG620 & $($ nadC-aceE) $\Delta 39$ & Formerly C $\Delta 39$ \\
\hline JRG1173 & mutT1 & $\lambda^{\mathrm{s}}$ derivative of T94A \\
\hline JRG1174 & aceE2 & $\lambda^{\mathrm{s}}$ derivative of $\mathrm{A} 2 \mathrm{~T} 3$ \\
\hline JRG1175 & aceE6 & $\lambda^{\mathrm{s}}$ derivative of $\mathrm{A} 6$ \\
\hline JRG1176 & aceFIO & $\lambda^{\mathrm{s}}$ derivative of $\mathrm{A} 10$ \\
\hline
\end{tabular}

(Langley \& Guest, 1977, 1978). Mutator activity was tested by replica-plating or direct application of drops of stationary phase cultures on $\mathrm{L}$ agar containing rifampicin $\left(100 \mu \mathrm{g} \mathrm{ml}^{-1}\right)$ or, better, streptomycin $(100 \mu \mathrm{g}$ $\mathrm{ml}^{-1}$ ).

Transduction. Spot transductions were performed by placing serially diluted lysates on to plates of selective media with seeded overlayers $(2.5 \mathrm{ml})$ containing $2 \times 10^{8}$ recipient bacteria and $\mathrm{MgSO}_{4}(10 \mathrm{~mm})$. Quantitative transductions were performed by incubating $2 \times 10^{8}$ recipient bacteria in $0.2 \mathrm{ml} \mathrm{MgSO}_{4}(10 \mathrm{~mm})$ with $0.1 \mathrm{ml}$ of serially diluted phage lysate [containing $10^{2}$ to $10^{10}$ plaque-forming units (p.f.u.)] for $15 \mathrm{~min}$ at $20^{\circ} \mathrm{C}$ before plating as an overlay on appropriate selective media using soft water agar. The selective conditions were based on the nutritional characteristics of the recipients and have been described in detail previously (Langley \& Guest, 1978). Incubation was at 30 or $37^{\circ} \mathrm{C}$ depending on the phage, and transductants were scored daily for up to $5 \mathrm{~d}$. The frequency of transduction was determined by comparison with the plaqueforming activity determined in parallel assays with E. coli $\mathrm{C} 600$ as indicator and BBL medium.

Phage lysates and DNA preparation. Phage preparations for DNA extraction were made by infecting exponentially growing cultures of $E$. coli $\mathrm{C} 600(200 \mathrm{ml})$ in $\mathrm{L}$ broth containing $\mathrm{MgSO}_{4}(10 \mathrm{~mm})$; lysis was completed with $\mathrm{CHCl}_{3}\left(0.5 \mathrm{ml} \mathrm{l}^{-1}\right)$ and $\mathrm{NaCl}\left(40 \mathrm{~g} \mathrm{l}^{-1}\right)$ was added. The crude lysate was then treated with RNAase and DNAase ( $1 \mu \mathrm{g} \mathrm{ml}^{-1}$ each, $1 \mathrm{~h}$ at room temperature), clarified by centrifuging ( $15 \mathrm{~min}$ at $5000 \mathrm{~g}$ ) and the phages were concentrated with polyethylene glycol 6000 according to Yamamoto et al. (1970). Purification was achieved by centrifuging the suspension $(9 \mathrm{ml})$ into a discontinuous gradient $(5 \mathrm{ml})$ of buffered $\mathrm{CsCl}$ solutions (densities $1.3,1.5$ and $1.7 \mathrm{~g} \mathrm{ml}^{-1}$ ) for $2 \mathrm{~h}$ at $33000 \mathrm{rev} \cdot \mathrm{min}^{-1}$ and $25^{\circ} \mathrm{C}$ in the $6 \times 14 \mathrm{ml}$ rotor of a Prepspin 50 centrifuge (MSE). The phage band was collected and dialysed against $\mathrm{Tris} / \mathrm{HCl}$ (10 mM; pH 8.0) plus EDTA (1 mM) and the DNA was extracted using phenol and dialysed against the same buffer (Kaiser \& Hogness, 1960).

Restriction endonuclease techniques and agarose gel electrophoresis. The methods used for DNA digestion with restriction endonucleases and the analysis of restriction fragments by electrophoresis in agarose gels have been described previously (Cole \& Guest, 1980). Standards covering the range 23.7 to $0.59 \mathrm{~kb}$, obtained by digesting lambda ( $\lambda c$ I857) DNA with R.HindIII, R.EcoRI and R.HindIII plus R.EcoRI, were included in several tracks on all gels to provide a calibration for fragment size relative to mobility. The sizes of the standard fragments are based on the lambda restriction map of P. Philippsen \& R. W. Davis (personal communication, 1978). The enzymes R.HindIII, R.EcoRI, R.BamHI, R.BglII, R.KpnI and R.XhoI were kindly provided by Professor K. and Dr N. E. Murray, and R. SmaI (Boehringer), R.Sst I, R.SalI and R.AvaI (Uniscience) were commercial samples.

Electron microscopy. Heteroduplex molecules were made and observed by the methods of Davis et al. 

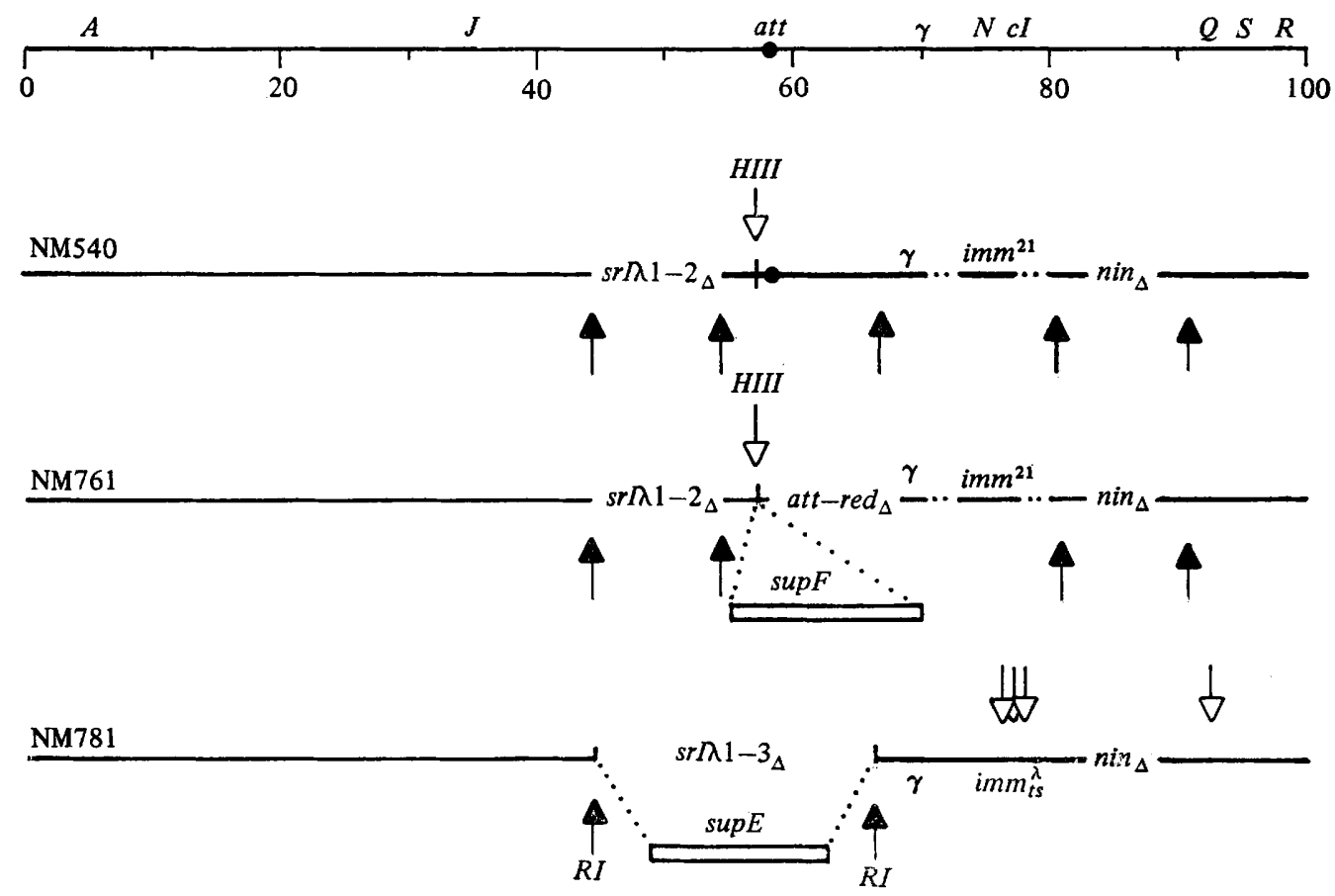

Fig. 1. Diagram illustrating the characteristics of the vector phages: NM540, R.HindIII insertion vector; NM761, R.HindIII replacement vector; NM781, R.EcoRI replacement vector. The map at the top shows some of the genetic markers in the $\lambda$ genome. The filled arrows represent R.EcoRI targets, open arrows the R.HindIII targets; the cloning sites are marked $R I$ and $H I I I$, respectively. - marks the position of the $\lambda$ attachment site. Gaps indicate deletions, dotted lines denote the deletion associated with the substitution of the immunity region and the double lines identify the bacterial restriction fragments present in replacement vectors.

(1971) in solutions containing (final concentration) Tris/ $\mathrm{HCl}(100 \mathrm{~mm}, \mathrm{pH} 8 \cdot 6)$, EDTA (10 mM), formamide $(48 \%, \mathrm{v} / \mathrm{v})$ and cytochrome $c\left(0.18 \mathrm{mg} \mathrm{ml}^{-1}\right)$. Molecules were mounted on parlodion films, stained with uranyl acetate, rotary shadowed with platinum and viewed in a Siemens Elmiskop 101 electron microscope at accelerating voltage of $80 \mathrm{kV}$ and $20000 \times$ magnification. The micrographs were enlarged photographically and contour lengths were determined with a map measurer.

Enzymology. Cultures were grown aerobically in glucose minimal medium supplemented with acetate and succinate, harvested and ultrasonic extracts were prepared for enzymology according to Langley \& Guest (1977). The methods for assaying overall pyruvate dehydrogenase complex, pyruvate dehydrogenase (E1; EC 1.2.4.1) plus pyruvate oxidase (when present), dihydrolipoamide acetyltransferase (E2; EC 2.3.1.12) and lipoamide dehydrogenase (E3; EC 1.6.4.3) have also been described previously (Langley \& Guest, 1977). Enzyme activities in ultrasonic extracts are expressed as $\mu$ mol substrate transformed (mg protein $)^{-1} \mathrm{~h}^{-1}$.

\section{RESULTS}

\section{Isolation of $\lambda$ nadC and $\lambda$ lpd transducing phages}

Populations of artificially constructed recombinant phages made by the incorporation of R.HindIII and R.EcoRI fragments of $E$. coli DNA in the $\lambda$ vectors NM540, NM761 and NM781 (Fig. 1) were screened for transducing phages which complemented the metabolic lesions of nadC, aceE, aceF and $l p d$ mutants using appropriate nutritional selections. This multi-faceted approach was adopted because the estimated size for the coding sequence of the pyruvate dehydrogenase complex, based on the sizes of its three components, is large ( $6.5 \mathrm{~kb}$ approx.). It was reasoned that the complete sequence was likely to be disrupted by the presence of internal targets for the two restriction endonucleases, whereas the individual 
genes, or the neighbouring nadC gene, may be released intact. If so, the combination of in vitro methods plus in vivo extension of a cloned segment could be used to isolate the entire ace-lpd region. Accordingly, several mutants deleted for the nadC-aroP $(\Delta 2)$, nadCace $E(\Delta 22)$, nadC-ace $F(\Delta 10)$ and aroP-lpd $(\Delta 18)$ regions as well as aceE (JRG73) and lpd (JRG354, JRG355) point mutants were used as recipients. No transduction of the ace genes was detected with any of the three populations of recombinant phages, but they all transduced the nadC gene and lysates derived from the R.EcoRI vector (NM781) transduced the $l p d$ gene. Representative $\lambda$ nadC and $\lambda l p d$ phages were isolated from transduction plaques or, in the case of $\lambda$ nadC derivatives of NM 540, induced from transductant colonies. Those to be described include (with the corresponding vector): $\lambda$ nadC-G75N(NM540), G76N(NM761) and G78N (NM781) - and $\lambda l p d-G 81 L, G 82 L$ and G83L (all NM781 derivatives) - where $\mathrm{N}$ and $\mathrm{L}$ denote their initial selection as $\lambda$ nadC and $\lambda l p d$ transducing phages, respectively. Two distinct and independent types of $\lambda l p d$ phages were detected on the basis of the rate at which the transductant plaques developed. With phages represented by G81L and G83L the initial size of the transductant plaque was reproducibly greater than with those of the G82L type. Preliminary genetic studies using a variety of recipients deleted in the $n a d C-l p d$ region and selecting for $\mathrm{Nad}^{+}$or $\mathrm{Lpd}^{+}$transductants indicated that all the $\lambda$ nadC phages, but none of the $\lambda l p d$ phages, expressed the wild-type aroP gene. This was confirmed with lysogens and dilysogens (with $\lambda \mathrm{imm}^{\mathbf{4 3 4}}$ ) which had been isolated without any nutritional selection. Likewise, it appeared that none of the $\lambda$ nadC or $\lambda l p d$ phages expressed functional $a c e E^{+}$or $a c e F^{+}$genes capable of complementing the nutritional lesions of the corresponding mutants. This indicated that the ace region probably contains restriction targets for both R.EcoRI and R.HindIII.

\section{Isolation of $\lambda$ nadC and $\lambda$ lpd phages with extended transducing ranges}

Plaque-forming phages containing the entire ace-lpd region were selected after in vivo extension of the cloned nadC-aroP and $l p d$ fragments in opposite directions to incorporate the ace genes and generate phages with overlapping sequences in the aroP-aceE-aceF-lpd region. The $\lambda$ nad $C$ and $\lambda l p d$ phages were established as prophages by recombination close to, or within, the host nadC and lpd genes, and $\lambda$ nadC-lpd and $\lambda$ ace-lpd phages, generated by excision errors, were selected following induction of the respective prophages (see examples in Fig. 2). All the starting phages except G75N are integration-deficient so that lysogeny by recombination in the region of shared chromosomal homology was favoured. In addition, a host (KS302) lacking the normal lambda attachment site was used in order to increase the probability of the same type of integration occurring with $\mathrm{G} 75 \mathrm{~N}$. The lysates obtained by u.v.-irradiation or thermal induction (NM781 derivatives only) of the lysogens were used to transduce several $l p d$ and ace mutant recipients with appropriate nutritional selections. The frequencies of $\mathrm{Lpd}^{+}$and Ace ${ }^{+}$transduction were about $10^{-7}$ transductants per p.f.u. All types of transductant were included: colonies, clusters of colonies (galaxies) and transductant plaques.

The lysogens should contain the lambda genome incorporated in one of two orientations dictated by the orientation of the cloned segment of bacterial DNA within the phages. Furthermore, aberrant excisions should extend the segments of bacterial DNA to incorporate the ace-lpdregion or the aceE,F genes with alterations of the phage genotype which are diagnostic of the orientations of both the prophages and the cloned DNAs relative to the bacterial chromosome. Thus, extensions in one direction are likely to generate defective transducing phages as a consequence of deleting essential phage genes in the left arm (e.g. $J$ ). By contrast, extensions in the opposite direction can generate transducing phages which lack the red and gam genes and these are easily recognized by their plating ability on P2 lysogens, the Spi- phenotype (Zissler et al., 1971). In order to investigate the orientations of the cloned segments the sub-populations of $\mathrm{Spi}^{-}$phages in the induced lysates were enriched 


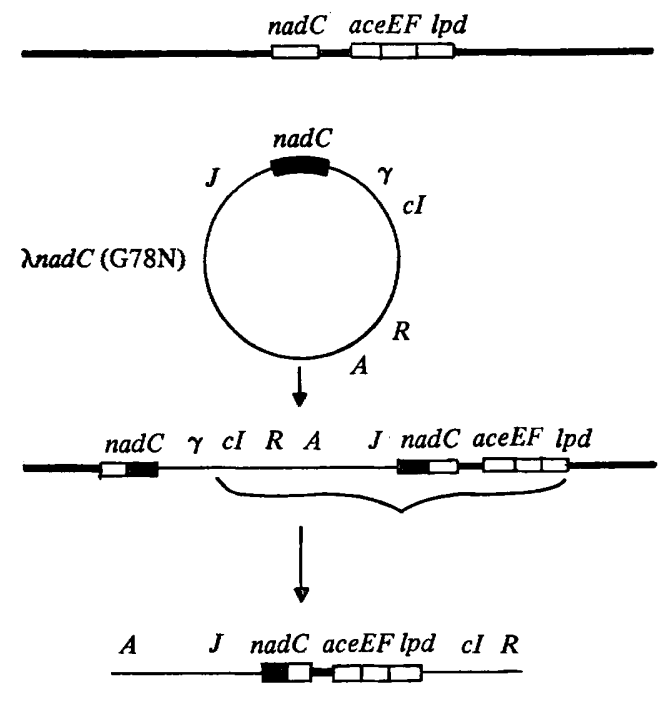

$\lambda$ nadC-lpd (G90)

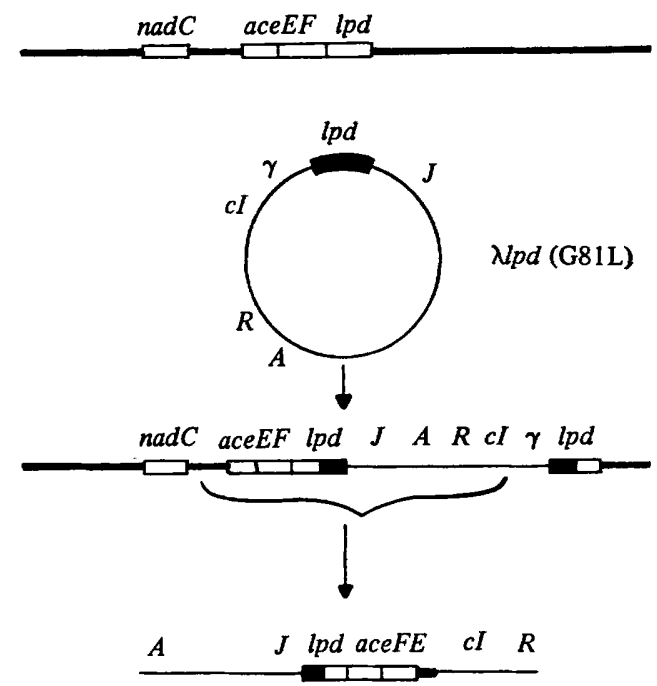

Nlpd-ace (G91-G94)

Fig. 2. Diagrammatic representation of the extension of the transducing ranges of $\lambda$ nadC and $\lambda l p d$ phages by integration in the region of bacterial DNA homology and aberrant excision of the transducing prophages. The orientations of the inserted genes (in boxes) correspond to the situations presented by $\mathrm{G} 78 \mathrm{~N}(\lambda$ nadC $)$ and G81L $(\lambda l p d)$ based on the gene order in the bacterial chromosome (thick line) and the enrichment of the respective phage derivatives (G90 and G91-G94) by $\mathrm{Spi}^{-}$ selection.

on lawns of $E$. coli $\mathrm{C} 600(\mathrm{P} 2)$ to see whether or not their transducing activities were simultaneously enriched. The frequencies of $\mathrm{Lpd}^{+}$transduction were increased 500 -fold (G78N) and 5000 -fold (G75N and $\mathrm{G} 76 \mathrm{~N}$ ) after Spi- enrichment indicating that bacterial genes are inserted with a clockwise orientation relative to the vegetative phage: $\lambda$ nadC-lpd $(\lambda A \cdots J \cdot n a d C-a c e-l p d \cdots R)$. Likewise, the frequency of $\mathrm{Ace}^{+}$transduction was increased 400 -fold after Spi- enrichment of the G81L-derived lysate and this is diagnostic of an anticlockwise orientation of the bacterial genes: $\lambda l p d-a c e(\lambda A \cdots J \cdot I p d-a c e F-a c e E \cdots R)$. The origin of these phages from G78N and G81L is shown diagrammatically in Fig. 2. By contrast, no increase in $\mathrm{Ace}^{+}$transduction was observed after $\mathrm{Spi}^{-}$selection of the phages induced from the lysogen of G82L. This suggests that the lpd region of G82L is inserted with the opposite polarity to that in G81L. In fact, no plaque-forming $\lambda$ ace-lpd phages were ever obtained by extending the G82L phage. Presumably the lysates contained defective Ace $^{+}$transducing phages $(\lambda \mathrm{d} a c e-l p d)$ and this would be consistent with the predicted orientation of the lpd region in G82L.

Plaque-forming phages with extended transducing ranges were purified from the Spienriched lysates and representative phages were selected for further studies. The $\lambda$ nadC-lpd phages were G87 (from G75N), G88 (from G76N) and G90 (from G78N). Of these G87 and G88 formed clear plaques and needed a helper phage (usually NM540) for successful transduction. Phage G90 was less defective, it produced speckled plaques and did not need a helper phage for transduction. Several $\lambda l p d$-ace phages, G91 to G94, all retained the temperature-sensitive immunity of G81L but transduction of some recipients was improved by presence of a helper $\left(\lambda^{+}\right)$. 


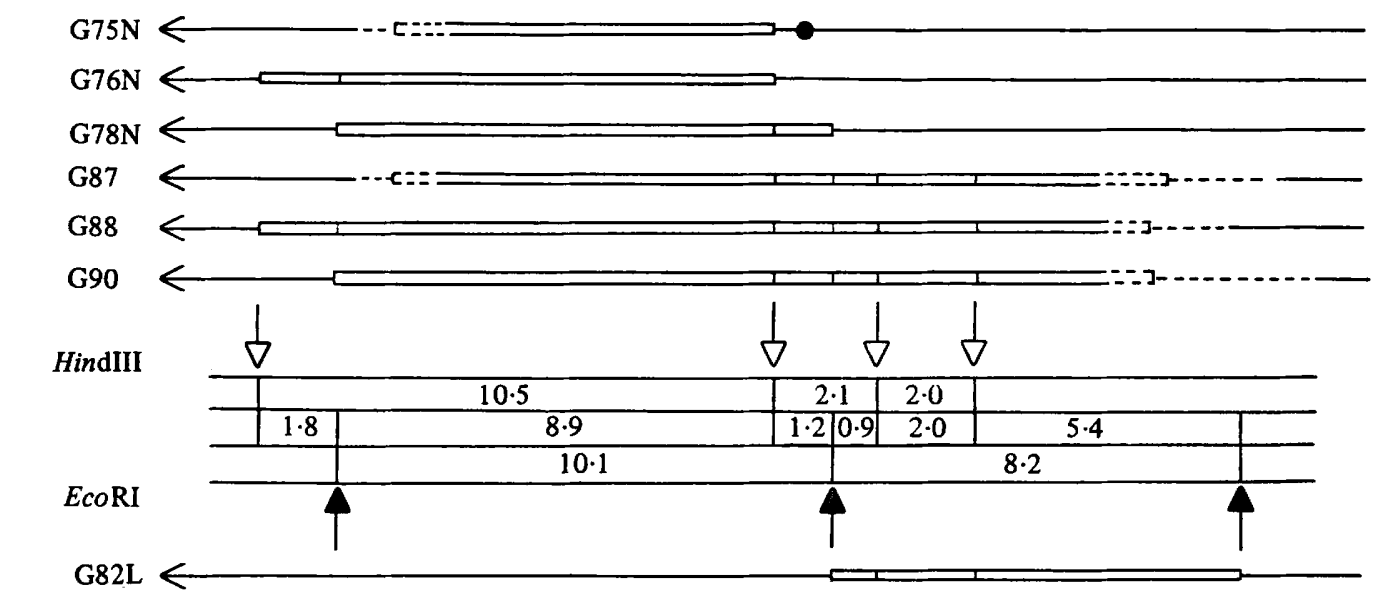

G81L, G83L

G91-G94

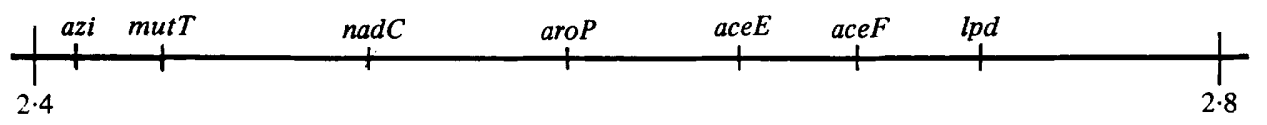

Fig. 3. Physical map of the nadC-lpd region of Escherichia coli deduced from the structures of the genomes of the transducing phages used in this investigation; drawn to scale. Vector DNA is indicated by single lines with the arrowheads pointing leftwards towards the head gene region of the phage DNA. Bacterial DNA is indicated by the double lines and the dashed lines denote regions where the transition from bacterial to phage DNA is uncertain. indicates the phage attachment site. The segments of bacterial DNA have been aligned and, where necessary, the orientation of the vector arms have been reversed. R.Eco RI targets are denoted by filled arrows and R.HindIII targets by open arrows; the numbers refer to fragment lengths in kilobase pairs (kb). Approximate positions of the genes in the bacterial chromosome $(2.4$ to $2.8 \mathrm{~min})$ are indicated in the segment of genetic map at the bottom.

\section{Restriction analysis of $\lambda$ nad,$\lambda l p d$ and derivative phages}

DNA from each of the 13 phages and the three vector phages was digested with restriction endonucleases R.HindIII and R.EcoRI, both separately and in combination. The resulting fragments were separated by electrophoresis in agarose gel and calibrated using standard digests of lambda ( $\lambda c$ I857) DNA. A physical map of the nadC-lpd region of the $E$. coli chromosome was then deduced from the restriction maps of the transducing phage genomes (Fig. 3).

The bacterial DNA in all three $\lambda$ nadC phages was inserted with the same orientation. In the NM540 derivative (G75N) a fragment estimated at between 5.7 and $9.0 \mathrm{~kb}$ was fused to the left arm of the vector. The NM761 (G76N) and NM781 (G78N) derivatives contained overlapping R.HindIII $(10.5 \mathrm{~kb})$ and R.EcoRI $(10.1 \mathrm{~kb})$ fragments comprising a common segment of $9.0 \mathrm{~kb}$ adjacent to $1.8 \mathrm{~kb}$ and $1.2 \mathrm{~kb}$ sub-fragments, respectively (Fig. 3).

The $\lambda l p d$ phages contained identical R.EcoRI insertions of $8.2 \mathrm{~kb}$ and sub-fragments of $0 \cdot 9,2.0$ and $5 \cdot 4 \mathrm{~kb}$ generated after further digestion with R.HindIII. However, single digestion with R.HindIII showed that the bacterial DNA is inserted with opposing polarities in G81L and G83L relative to G82L (Fig. 3). Since the isolation of these $\lambda$ lpd transducing phages relied on the complementation of lpd mutants, expression of the cloned lpd must occur regardless of its orientation in the phage genome, but there must be some orientationdependent effect on expression to account for the observed differences in transducing activity.

The three extended $\lambda$ nadC phages (G87, G88 and G90; $\lambda$ nadC-lpd) had gained the two R.HindIII targets responsible for the 0.9 and $2.0 \mathrm{~kb}$ sub-fragments of the $\lambda l p d$ phages. In 


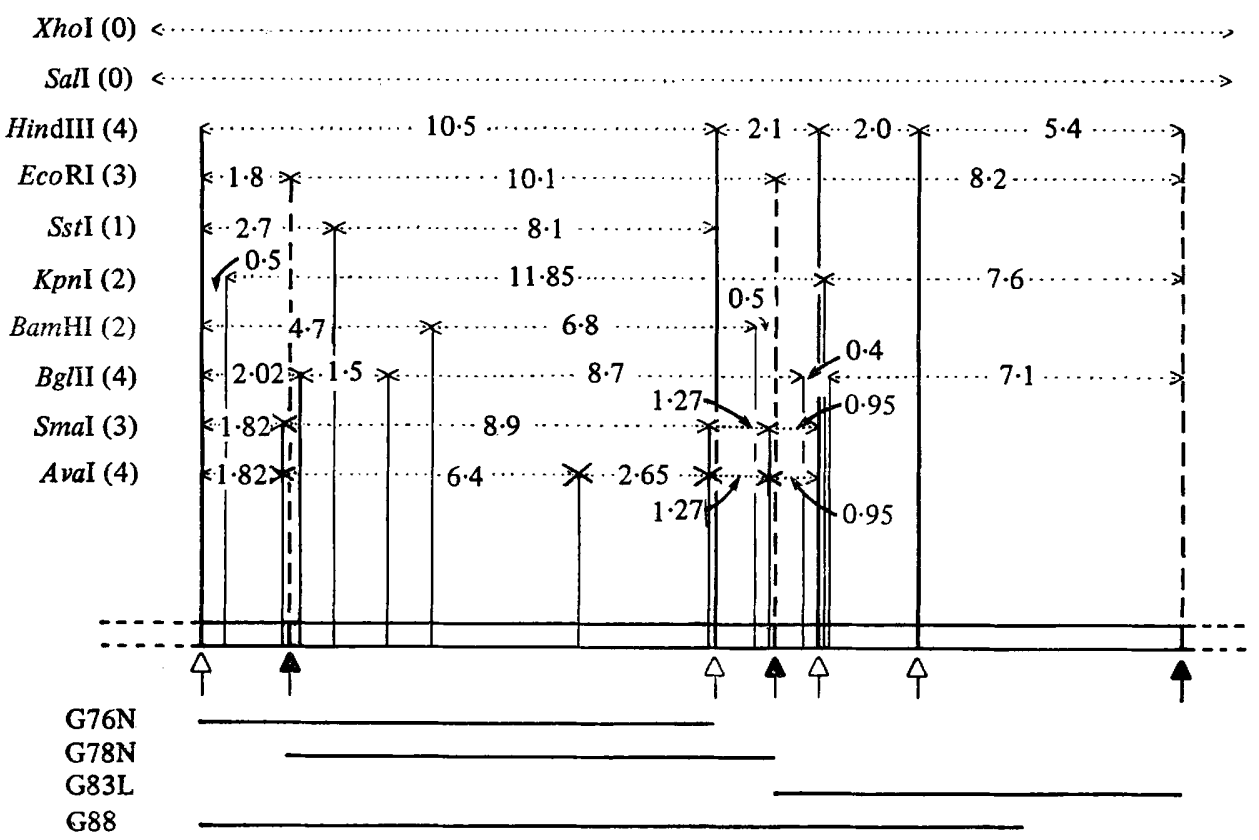

Fig. 4. Scale map of the nadC-lpd region of the bacterial chromosome based on the fragmentation of $\lambda$ nadC (G76N, G78N), $\lambda$ lpd (G83L) and $\lambda$ nadC-lpd (G88) transducing phages by the corresponding restriction endonucleases. The number of targets for each enzyme is shown in parentheses. The orientation (left to right) corresponds to a nadC-lpd (clockwise) orientation of the bacterial chromosome. The R.HindIII and R.EcoRI targets are indicated by open and filled arrows, respectively. The sizes are shown in kilobase pairs $(\mathrm{kb})$ for key fragments (other fragments are listed in Table 2). The segments of bacterial DNA contained by specific phages are shown below the map.

each case the extensions had modified the structures of the right arms of the parental phages: $\operatorname{sr} I \lambda 3$ was deleted in G87 and the $\operatorname{srI} \lambda 3-4$ (G87), $\operatorname{shn} \lambda 3-\operatorname{sr} I \lambda 4$ (G88), and $\operatorname{sr} I \lambda 3-\operatorname{shn} \lambda 4$ (G90) fragments were replaced by hybrid fragments containing bacterial and phage DNA. This confirms the conclusion based on the Spi- selection, that incorporating the lpd gene is accompanied by an aberrant excision affecting the right arm. One fragment $(2 \cdot 1 \mathrm{~kb})$ in all the R.HindIII digests was clearly identifiable as linking the double-digestion products $(1.2$ and $0.9 \mathrm{~kb}$ ) of the NM781-derived $\lambda$ nadC and $\lambda l p d$ phages (G78N and G81L, G82L and G83L). This not only shows that the R.EcoRI fragments of the $\lambda$ nadC and $\lambda l p d$ phages are adjacent in the $E$. coli chromosome, it further defines their orientation relative to the $E$. coli linkage map because the $l p d$ gene is located clockwise to nadC (Fig. 3). The $\lambda$ nadC-lpd phages each contained hybrid fragments of $6.1 \mathrm{~kb}$ (G87), $5.2 \mathrm{~kb}$ (G88) and $6.8 \mathrm{~kb}(\mathrm{G} 90)$ in which the extended bacterial segment is fused to a segment of phage DNA to the left of the nearest vector target ( $\operatorname{sr} I \lambda 4, \operatorname{sr} I \lambda 4$ and $\operatorname{shn} \lambda 4$, respectively).

Studies with three $\lambda l p d$-ace phages (G91, G93 and G94) showed that each had incorporated an extra R.HindIII target $1.2 \mathrm{~kb}$ from the parental R.EcoRI target and hybrid fragments of $6.2 \mathrm{~kb}$ (G91), $5.5 \mathrm{~kb}$ (G93) and $4.2 \mathrm{~kb}$ (G94) between this new R.HindIII target and the R.HindIII target (shn $\lambda 4)$ in the immunity region of G81L, the parental $\lambda l p d$ (Fig. 3). This confirmed both the polarity of the extensions, originally predicted from the Spi- selection, and the DNA structure between nadC and $l p d$.

The fragments generated by R.EcoRI and R.HindIII, separately and in combination, unambiguously define the organization and orientation of DNA containing the nadC, aroP, aceE, ace F and $l p d$ genes of E. coli (Fig. 3). 


\section{Table 2. Restriction fragments derived from the nadC-lpd region of the E. coli chromosome}

\begin{tabular}{|c|c|c|c|c|}
\hline \multicolumn{5}{|c|}{$\begin{array}{l}\text { DNA fragments of bacterial origin were generated by digesting four transducing phages (G76I } \\
\text { G78N, G83L and G88) with the indicated enzyme alone or in conjunction with R.HindIII } \\
\text { R.EcoRI. A consistent and unambiguous map based on the fragmentation patterns is shown } \\
\text { Fig. } 4 \text {. The fragments are listed according to their terminal sequences, and in order to identify th } \\
\text { positions of double-digestion products in the physical map, fragments possessing targets for th } \\
\text { variable enzyme at the left-hand extremity are shown in italics. No targets for R.XhoI or R.Sa } \\
\text { were detected. Average values derived from several independent determinations are given } \\
\text { kilobase pairs (kb). Fragments of less than } 0.3 \mathrm{~kb} \text { were not detected but their existence can } \\
\text { predicted and this is indicated by an asterisk. Fragments overlapping bacterial and vector DN } \\
\text { are not included. } \\
\text { Fragments of bacterial origin (kb) generated by the } \\
\text { specified restriction endonuclease }\end{array}$} \\
\hline endonuclease & targets & Alone & + R.HindIII & + R.EcoRI \\
\hline R.Sst I & 1 & - & $8 \cdot 1,2 \cdot 7$ & $9 \cdot 2,0.98$ \\
\hline R.KpnI & 2 & $11 \cdot 85$ & $10 \cdot 7,1 \cdot 95,0 \cdot 5, *$ & $7 \cdot 6,1 \cdot 31,0 \cdot 98$ \\
\hline R.BamHI & 2 & $6 \cdot 8$ & $6 \cdot 3,4 \cdot 7,1 \cdot 35,0 \cdot 76$ & $2.9,0.51$ \\
\hline R. $B g / \mathrm{II}$ & 4 & $8 \cdot 7,1 \cdot 5,0.4$ & $\begin{array}{l}7 \cdot 2,2 \cdot 02,1 \cdot 93,1 \cdot 82 \\
0 \cdot 32, *\end{array}$ & $8 \cdot 0,7 \cdot 1,0 \cdot 52, *$ \\
\hline R.SmaI & 3 & $8 \cdot 9,1 \cdot 27$ & $1.82,1 \cdot 12,0.95, *$ & \\
\hline R.AvaI & 4 & $6 \cdot 4,2 \cdot 65,1 \cdot 27$ & $1.82,1.08,0.95$, * & $6 \cdot 3, *, *$ \\
\hline
\end{tabular}

A detailed physical map of the nadC-lpd region of the bacterial chromosome was constructed by analysing the cleavage fragments obtained by digesting transducing phage DNAs using restriction endonucleases BamHI, BglII, KpnI, SalI, XhoI, Sst I, AvaI, SmaI with and without HindIII, EcoRI and HindIII plus EcoRI. Four phages were used: three recombinant phages (G76N, G78N and G83L) and one derivative (G88, $\lambda$ nadC-lpd) to provide segments of DNA overlapping the R.EcoRI and R.HindIII fragments cloned in recombinant phages. No targets for R.SalI and R.XhoI were detected but targets for the other enzymes were located at positions defined by the sizes of the digestion products (Table 2; Fig. 4). A completely self-consistent and unambiguous order of restriction targets was established. Half of the restriction targets were clustered in a $2.5 \mathrm{~kb}$ region containing the $2.1 \mathrm{~kb}$ R.HindIII fragment, but no targets were found in the $5.4 \mathrm{~kb} \mathrm{R}$.HindIII plus R.EcoRI double-digestion product of the $\lambda l p d$ phages.

\section{Electron microscopic heteroduplex studies}

The opposing polarities of the lpd regions in G82L and G83L were confirmed by electron microscopic analysis of heteroduplex molecules (Fig. $5 \mathrm{a}$ ). The regions of single-strand nonhomology were the same length and originated at the appropriate position in the phage genome. From photographs of 14 independent heteroduplex molecules, each accompanied by at least one $\phi X 174$ marker, the region of non-homology was estimated as $7.7 \pm 0.42 \mathrm{~kb}$ flanked by homologous regions of $21.9 \pm 0.5$ and $14.65 \pm 0.61 \mathrm{~kb}$. This is in reasonable agreement with values of $8.2 \mathrm{~kb}$ for the inserted DNA and 21.8 and $13.9 \mathrm{~kb}$ for the vector DNA, based on restriction analysis. The $\lambda$ nadC-lpd and $\lambda l p d$-ace phages should possess a common segment of bacterial DNA containing the $a c e E, a c e F$ and $l p d$ genes. To locate this region and estimate its size, heteroduplex molecules of two phages (G88 and G94) with oppositely polarized inserts and differing immunity were examined (Fig. $5 b, c$ ). Most of the molecules contained a single and unequal region of non-homology $(13.4 \pm 0.6$ and 18.6 \pm $0.9 \mathrm{~kb}$ ) flanked by homologous regions representing the left and right extremities of the lambda genome, $21 \cdot 26 \pm 0.76$ and $7.04 \pm 0.02 \mathrm{~kb}$, respectively (Fig. $5 b$ ). No separate region corresponding to the different immunities was detected indicating that the segment of homology between the cloning site and the immunity region had been deleted, in one or 

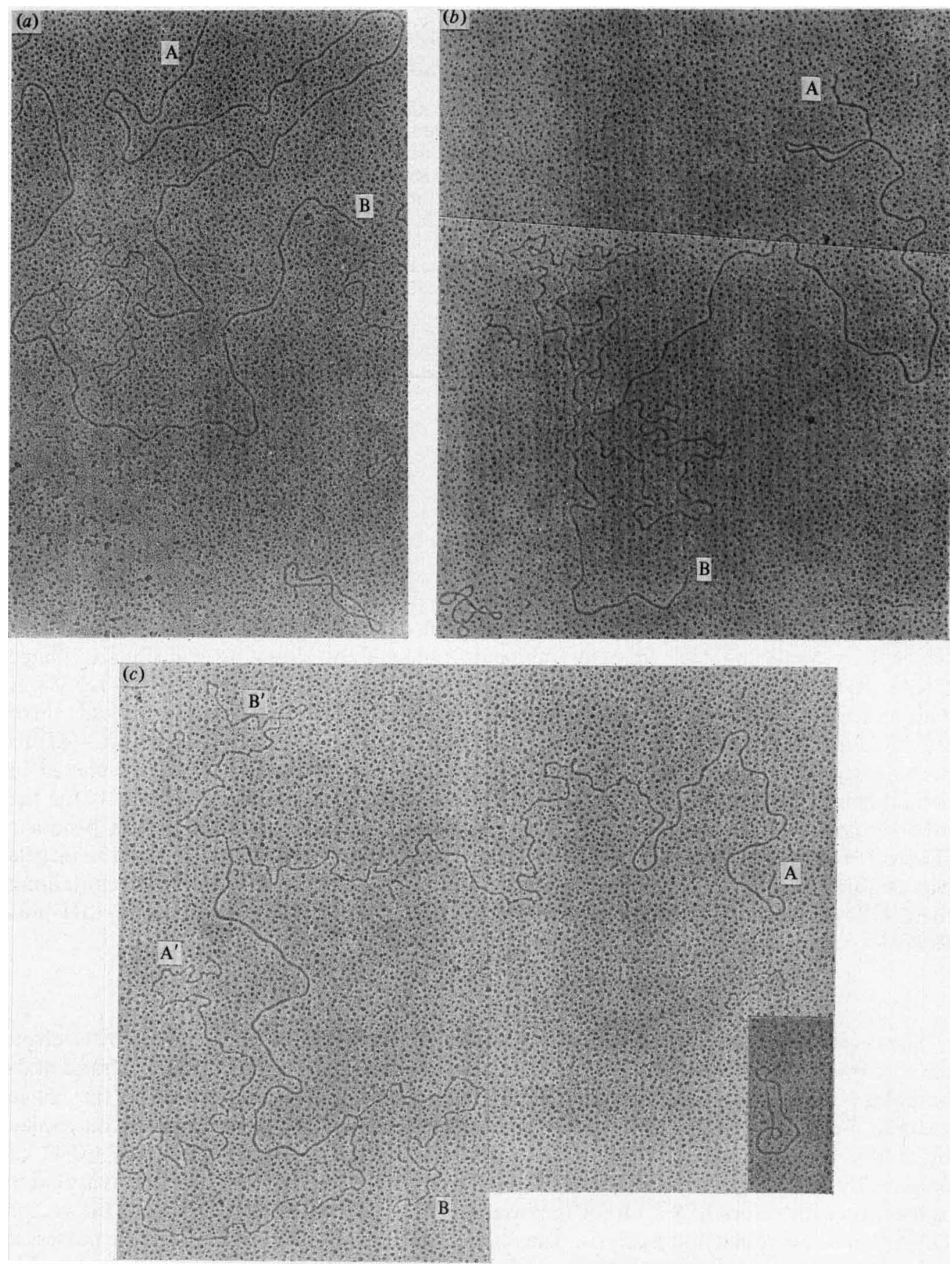

Fig. 5. Electron micrographs of heteroduplex molecules of lambda transducing phages containing oppositely polarized segments of bacterial DNA. The extremities of the left (A) and right (B) arms of the phage genomes are indicated. Phage $\phi \times 174$ replicative $(5.386 \mathrm{~kb})$ was included as a standard length marker. (a) Two $\lambda l p d$ derivatives, G82L and G83L; (b) $\lambda$ nadC-lpd (G88) and $\lambda l p d-a c e$ (G94); (c) the same phages as in (b) with the ends identifiable as A, B ( $\lambda$ nad $C-l p d, \mathbf{G} 88)$ and $\mathbf{A}^{\prime}, \mathbf{B}^{\prime}$ ( $\lambda$ lpd-ace, G94). 


\title{
Table 3. Specific activities of the pyruvate dehydrogenase complex and components in dilysogenic derivatives of ace and lpd mutants
}

\begin{abstract}
Ultrasonic extracts of cultures grown on glucose-based media were prepared and assayed as described in Methods. The activities of the dilysogens are compared with the original mutant containing the helper prophage and its parental strain. The series of strains derived from K1-1 all lack pyruvate oxidase, which is present in the other strains and is active in the assay for the E1 component. Specific activities are expressed as $\mu \mathrm{mol}$ substrate transformed (mg protein) ${ }^{-1} \mathrm{~h}^{-1}$. Abbreviations: pdhc, overall pyruvate dehydrogenase complex; E1, pyruvate dehydrogenase, plus oxidase when present; E2, dihydrolipoamide acetyltransferase; E3, lipoamide dehydrogenase.
\end{abstract}

\begin{tabular}{|c|c|c|c|c|c|}
\hline \multirow[b]{2}{*}{ Strain } & \multirow[b]{2}{*}{ Relevant genotype } & \multicolumn{4}{|c|}{ Specific activity } \\
\hline & & pdhc & E1 & E2 & E3 \\
\hline $\begin{array}{l}\text { K1-1 } \\
\text { JRG599 }\left(\lambda i^{434}\right) \\
\text { JRG599 }\left(\lambda i^{434} \lambda \mathrm{G} 82 \mathrm{~L}\right) \\
\left.\text { JRG599( } \lambda i^{434} \lambda \mathrm{G} 83 \mathrm{~L}\right) \\
\text { JRG599 }\left(\lambda i^{434} \lambda \mathrm{G} 93\right) \\
\left.\text { JRG599( } \lambda i^{434} \lambda \mathrm{G} 78 \mathrm{~N}\right) \\
\left.\text { JRG599 } \lambda i^{434} \lambda \mathrm{G90}\right)\end{array}$ & $\begin{array}{l}a^{+} e^{+} l p d^{+} \\
(\text {ace-lpd }) \Delta 18 \\
(\text { ace-lpd }) \Delta 18, \lambda l p d^{+} \\
(\text {ace-lpd }) \Delta 18, \lambda l p d^{+} \\
(\text {ace-lpd }) \Delta 18, \lambda l p d-a c e^{+} \\
(\text {ace-lpd }) \Delta 18, \lambda \text { nadC }^{+} \\
(\text {ace-lpd }) \Delta 18, \lambda \text { nadC-lpd }\end{array}$ & $\begin{array}{l}3 \cdot 37 \\
0 \cdot 02 \\
0 \cdot 07 \\
0 \cdot 04 \\
2 \cdot 23 \\
0.03 \\
1 \cdot 76\end{array}$ & $\begin{array}{l}1 \cdot 51 \\
0 \cdot 02 \\
0 \cdot 02 \\
0 \cdot 02 \\
0 \cdot 88 \\
0 \cdot 03 \\
1 \cdot 24\end{array}$ & $\begin{array}{r}6.69 \\
<0.01 \\
<0.01 \\
<0.01 \\
4.62 \\
<0.01 \\
4.50\end{array}$ & $\begin{array}{l}2 \cdot 51 \\
0 \cdot 02 \\
2 \cdot 57 \\
2 \cdot 38 \\
1 \cdot 58 \\
0 \cdot 02 \\
1 \cdot 57\end{array}$ \\
\hline $\begin{array}{l}\text { W1485E } \\
\left.\text { JRG73( } \lambda i^{434}\right) \\
\left.\text { JRG73( } \lambda i^{434} \lambda \text { G82L }\right) \\
\left.\text { JRG73( } \lambda i^{434} \lambda \text { G83L }\right) \\
\text { JRG73( } \lambda i^{434} \lambda \text { G93) } \\
\text { JRG73 }\left(\lambda i^{434} \lambda \text { G78N) }\right. \\
\text { JRG73( } \lambda i^{434} \lambda \text { G90) }\end{array}$ & 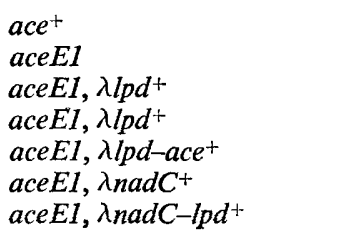 & $\begin{array}{l}2 \cdot 88 \\
0.03 \\
0 \cdot 14 \\
0 \cdot 10 \\
1 \cdot 83 \\
0 \cdot 02 \\
3.03\end{array}$ & $\begin{array}{l}1 \cdot 82 \\
0 \cdot 80 \\
1 \cdot 30 \\
1 \cdot 26 \\
1 \cdot 88 \\
0 \cdot 80 \\
1 \cdot 46\end{array}$ & $\begin{array}{r}5 \cdot 78 \\
11 \cdot 06 \\
7 \cdot 90 \\
8 \cdot 00 \\
8 \cdot 88 \\
9 \cdot 33 \\
6 \cdot 52\end{array}$ & $\begin{array}{l}1 \cdot 82 \\
1 \cdot 50 \\
1 \cdot 69 \\
2 \cdot 18 \\
1 \cdot 58 \\
1 \cdot 68 \\
1 \cdot 65\end{array}$ \\
\hline $\begin{array}{l}\text { H } \\
\left.\text { JRG355( } \lambda i^{434}\right) \\
\left.\text { JRG355( } \lambda i^{434} \lambda G 82 L\right) \\
\left.\text { JRG355( } \lambda i^{434} \lambda G 83 L\right) \\
\left.\text { JRG355( } \lambda i^{434} \lambda G 93\right) \\
\left.\text { JRG355( } \lambda i^{434} \lambda G 78 N\right) \\
\text { JRG355( } \lambda i^{434} \lambda \text { G90) }\end{array}$ & $\begin{array}{l}l p d^{+} \\
l p d-8 \\
l p d-8, \lambda l p d^{+} \\
l p d-8, \lambda l p d^{+} \\
l p d \cdot 8, \lambda l p d-a c e^{+} \\
l p d-8, \lambda \text { nadC } \\
l p d-8, \lambda \text { nadC-lpd } d^{+}\end{array}$ & $\begin{array}{l}5 \cdot 66 \\
0.07 \\
2 \cdot 24 \\
2 \cdot 16 \\
2.06 \\
0.08 \\
2.06\end{array}$ & $\begin{array}{l}1 \cdot 56 \\
0 \cdot 80 \\
3 \cdot 66 \\
1 \cdot 67 \\
3 \cdot 87 \\
1 \cdot 26 \\
3 \cdot 14\end{array}$ & $\begin{array}{r}8 \cdot 23 \\
10 \cdot 98 \\
7 \cdot 65 \\
6 \cdot 93 \\
8 \cdot 76 \\
5 \cdot 77 \\
8 \cdot 38\end{array}$ & $\begin{array}{l}1.81 \\
0.07 \\
1.76 \\
1.91 \\
2.06 \\
0.06 \\
2.26\end{array}$ \\
\hline
\end{tabular}

both phages, during extension of the incorporated bacterial DNA. The larger of the two single-stranded loops probably contains the nadC-lpd region of G88. A few of the molecules were paired so that the shared segment of bacterial DNA formed a duplex flanked by singlestranded ends containing bacterial and vector DNA (Fig. $5 c$ ). The size of the common region, estimated from 10 independent molecules, was $11.35 \pm 0.34 \mathrm{~kb}$ and the flanking regions were $28.4 \pm 0.66$ and $8.0 \pm 0.34 \mathrm{~kb}(\mathrm{~A}, \mathrm{~B} ; \mathrm{G} 88)$ and $22.42 \pm 0.64$ and $9.25 \pm 0.23 \mathrm{~kb}$ ( $\mathrm{A}^{\prime}, \mathrm{B}^{\prime}$; G94). This confirms that the phages containing oppositely polarized extensions share a continuous segment of homologous DNA overlapping in the aceE-aceF-lpd region. However, this segment is still about $4.8 \mathrm{~kb}$ larger than the size estimated for the coding sequence of the pyruvate dehydrogenase complex.

\section{Enzymological studies with dilysogens}

The transducing phages were isolated by their ability to complement the nutritional deficiencies of $l p d, a c e E, a c e F$ and $n a d C$ mutants. To establish whether the ace and $l p d$ genes are expressed from bacterial promoters, the nutritional and enzymological properties of a series of mutant and lysogenic strains were investigated. In the prophage state, transcription of the cloned genes is entirely dependent on bacterial promoters because initiation from phage promoters is repressed. Several mutants, JRG599 (aceE-lpd) $\Delta 18$, JRG73 (aceE1) and JRG355 (lpd-8), were infected with representative $\lambda$ imm $^{\lambda}$ phages, G82L $(\lambda l p d)$, G83L $(\lambda l p d)$, $\mathrm{G} 93(\lambda l p d-a c e), \mathrm{G} 78 \mathrm{~N}(\lambda$ nadC $)$ and G90 ( $\lambda$ nadC-lpd $)$ together with an integration-proficient helper $\left(\lambda i m m^{434}\right)$. The products with dual-immunity were expected to be dilysogens in which 
the helper and transducing phages were integrated in tandem within the attachment site in the bacterial chromosome. This outcome was confirmed by showing that, in each case, both of the resident prophages were cured by superinfection with a heteroimmune phage $\left(\lambda \mathrm{imm}^{21}\right)$ but not with an excision-defective heteroimmune phage ( $\lambda$ biol int-red imm $\left.^{21}\right)$. Growth tests were performed on appropriately supplemented minimal media with glucose, succinate and acetate as the major substrates. All the dilysogens carrying G90 and G93 possessed a wild-type nutritional phenotype, as did the dilysogenic derivatives of the $l p d-8$ strain carrying $\lambda l p d$ prophages (G82L and G83L). The latter prophages enabled the deletion strain $(a c e-l p d) \Delta 18$ to use acetate as substrate but growth on glucose and succinate still required supplementary acetate (i.e. only the $\mathrm{Lpd}^{-}$component of the combined $\mathrm{Ace}^{-} \mathrm{Lpd}^{-}$phenotype was reversed). None of the other combinations, including G78N and $\lambda i m m^{434}$ alone, had any effect on the nutritional phenotypes of the mutants. In every case curing was accompanied by the restoration of the original mutant phenotype.

Enzymological studies with dilysogenic derivatives of the deletion strain (JRG599, 118 ) established that the pyruvate dehydrogenase complex and its three component activities are restored in the presence of G90 ( $\lambda$ nadC-lpd) and G93 ( $\lambda l p d-a c e)$ prophages (Table 3). In the same host only the lipoamide dehydrogenase (E3) component was expressed from the $\lambda l p d$ prophages, G82L and G83L, and no significant orientation-dependent difference was detectable with these phages established as prophages. As expected, no functional components of the pyruvate dehydrogenase complex were expressed from the $\lambda$ nadC prophage (G78N). Similar studies with dilysogenic derivatives of the aceE1 (JRG73) and lpd-8 (JRG355) mutants confirmed that only the $l p d$ gene is expressed from the $\lambda l p d$ prophages, whereas the $a c e E$ and $l p d$ genes are expressed from the $\lambda$ nadC-lpd and $\lambda l p d-a c e$ prophages (Table 3). No significant gene dosage effects were observed in the dilysogens which are partial diploids.

The results provide conclusive evidence that the intact $l p d$ gene has been cloned with its own promoter and that it can be expressed independently of the ace operon. They show that the intact ace $E$ and $a c e F$ genes together with their promoter are present in phages with extended transducing ranges (G90 and G93). It can also be deduced that the R.EcoRI target situated between the $n a d C$ and $l p d$ genes resides within the ace $E$ gene or the ace promoter and not the $a c e F$ gene. If it were in the $a c e F$ gene or outside the ace operon then the pyruvate dehydrogenase component (aceE gene product) should have been expressed from the $\lambda$ nad $C$ or $\lambda l p d$ prophages, respectively. It follows that the $\lambda l p d$ phages contain an intact $a c e F$ gene which is not functional because it is divorced from the ace promoter.

\section{Genetic studies}

The total amount of bacterial DNA cloned in the $\lambda$ nadC and $\lambda l p d$ phages is $20 \mathrm{~kb}$ and this could code for several genes in addition to the nadC, aroP, aceE, aceF and lpd genes. However, only two genes, azi and $m u t T$, are known to be within reasonable proximity of the nadC gene (Fig. 3; Bachmann \& Low, 1980).

Linkage tests with all of $100 \mathrm{NadC}^{+}$transductants of the deletion strain JRG582 (azi, $n a d C$-aroP $P_{\Delta}$ ) obtained with each of the $\lambda$ nadC transducing phages (G75N, G76N and $\mathrm{G} 78 \mathrm{~N}$ ) retained the $\mathrm{Azi}^{\mathrm{R}}$ phenotype of the recipient, suggesting that the wild-type azi gene is not encoded by these phages.

The mutTl mutation is known to be recessive (Cox \& Yanofsky, 1969). However, the mutant phenotype (high frequency of spontaneous mutation to streptomycin resistance and rifampicin resistance) was unaffected by the presence of any of the $\lambda$ nadC prophages. It is concluded that the $\lambda$ nadC phages do not contain a functional mut $T$ gene, nor the azi gene, because $m u t T$ is located between azi and nadC. In this context, nine strains with deletions extending anticlockwise beyond the $\operatorname{nadC}$ gene $(\Delta 3, \Delta 10, \Delta 17, \Delta 22, \Delta 27, \Delta 32, \Delta 35, \Delta 39$ and $\Delta 42$; Langley \& Guest, 1978) were tested for increased rates of spontaneous mutation. 


\title{
Table 4. Mapping studies with transducing phages and ace mutants
}

\begin{abstract}
$\mathrm{Ace}^{+}$transductants were selected on enriched succinate minimal media after infecting recipient bacteria $\left(2 \times 10^{8}\right)$ with serial dilutions of the transducing phage lysates starting at a multiplicity of infection of 2. Transduction frequencies are expressed as numbers of Ace ${ }^{+}$colonies per $10^{6}$ phages added and the values obtained without phages (reversion frequencies) are expressed as numbers per $10^{6}$ recipient bacteria.
\end{abstract}

Frequency of $\mathrm{Ace}^{+}$transduction with phage:

\begin{tabular}{|c|c|c|c|c|c|c|c|}
\hline Recipient & Genotype & G76N & G78N & G82L & G83L & G93 & None \\
\hline JRG260 & aceE131 & $<0.20$ & 200 & $<0.20$ & $<0 \cdot 20$ & 1800 & $0 \cdot 15$ \\
\hline JRG 1174 & aceE2 & $<0.20$ & 250 & $<0 \cdot 20$ & $<0 \cdot 20$ & 1300 & 0.04 \\
\hline JRG1175 & aceE6 & $<0.20$ & $<0 \cdot 20$ & 37 & 52 & 770 & 0.04 \\
\hline JRG73 & aceE1 & $<0.01$ & $<0.01$ & 36 & 15 & 300 & 0.12 \\
\hline JRG 1176 & aceF10 & $<0.20$ & $<0.20$ & 850 & 1800 & 1900 & 0.03 \\
\hline JRG620 & $($ nad-aceE $) \Delta 39$ & $<0.05$ & 54 & $<0.03$ & $<0.02$ & 27 & 0.05 \\
\hline JRG616 & $($ nad-aceE $) \Delta 35$ & $<0.05$ & 58 & $<0.03$ & $<0.02$ & 90 & $0 \cdot 18$ \\
\hline JRG613 & $($ nad-aceE $) \Delta 32$ & $<0.01$ & 120 & $<0.01$ & $<0.01$ & 110 & $<0.01$ \\
\hline JRG593 & $($ aroP-aceE $) \Delta 13$ & $<0.01$ & 3 & $<0.01$ & $<0.01$ & 53 & 0.05 \\
\hline JRG615 & $(n a d-a c e E) \Delta 34$ & $<0.01$ & $<0.01$ & $<0.01$ & $<0.01$ & 19 & $<0.01$ \\
\hline JRG603 & $($ nad-ace $E) \Delta 22$ & $<0.01$ & $<0.01$ & $<0.01$ & $<0.01$ & 16 & $<0.01$ \\
\hline JRG590 & $($ nad-aceF $) \Delta 10$ & $<0.01$ & $<0.01$ & $<0.01$ & $<0.01$ & 120 & $<0.01$ \\
\hline JRG599 & $($ aroP-lpd $) \Delta 18$ & $<0.01$ & $<0.01$ & $<0.01$ & $<0.01$ & 120 & $<0.01$ \\
\hline
\end{tabular}

Such a phenotype could arise by deletion of the mut $T$ gene but no evidence supporting this possibility was obtained with any of the strains.

The aroP gene codes for the general aromatic amino acid permease, it is situated between $n a d C$ and $a c e E$ and it is inactivated by total or partial deletion in strains JRG590 $(\Delta 10$; $\left.n a d C-a c e F_{\Delta}\right)$ and JRG599 $\left(\Delta 18 ; \operatorname{aroP} l p d_{\Delta}\right)$. The growth of strains lacking the aroP function is resistant to the inhibitory analogues 5-methyltryptophan and $\beta$-thienylalanine. All the transducing phages were investigated for the presence of a functional aroP gene by several methods. These showed that all of $500 \mathrm{NadC}^{+}$transductants from the $\Delta 10$ strain obtained with six $\lambda$ nadC and $\lambda$ nadC-lpd phages had acquired the wild-type phenotype indicating that these phages carry the aroP gene. Comparable tests with $\mathrm{Lpd}^{+}$transductants of the $\Delta 18$ strain indicated that neither the $\lambda l p d$ phages nor the four $\lambda l p d$-ace phages (G90 to G94) carry a functional aroP gene. Further tests with a series of lysogenic and dilysogenic (plus $\lambda i m m^{434}$ ) derivatives of both the $\Delta 10$ and $\Delta 18$ strains confirmed that the intact aroP gene is only present in the six phages that carry nadC.

Genetic tests were also performed in order to correlate the physical and genetic maps of the nadC-lpd region, particularly with respect to the position of the ace operon (Fig. 3 ). The ace genes appear to be situated in the segment containing the three R.HindIII targets and the single R.EcoRI target. Representative transducing phages carrying bacterial DNA terminated by two of the critical restriction targets-R.HindIII (G76N, $\lambda$ nadC) and R.EcoRI (G78N, $\lambda$ nadC; G82L and G83L, $\lambda l p d)$ - were used to transduce a collection of genetically defined ace point and deletion mutants (Table 4). Phage G93 ( $\lambda l p d$-ace) was used as a positive control and acetate-independent $\left(\mathrm{Ace}^{+}\right)$transductants were selected. The failure of phage $\mathrm{G} 76 \mathrm{~N}$ to transduce any ace mutants indicated that the corresponding R.HindIII target is probably located outside and to the left of the ace operon. The other $\lambda$ nadC phage $(\mathrm{G} 78 \mathrm{~N})$ produced Ace ${ }^{+}$transductants with ace $E$ mutants possessing lesions in, or extending into, the promoter-proximal end of the ace $E$ gene (Table 4). The same mutants were not transduced by the $\lambda l p d$ phages (G82L, G83L), nor were any of the deletion mutants, because their deletions all enter the ace operon from the proximal end. However, aceE and $a c e F$ point mutants with distal lesions were transduced (Table 4). The corresponding R.EcoRI target would thus appear to be located in the aceE gene between the aceE2 


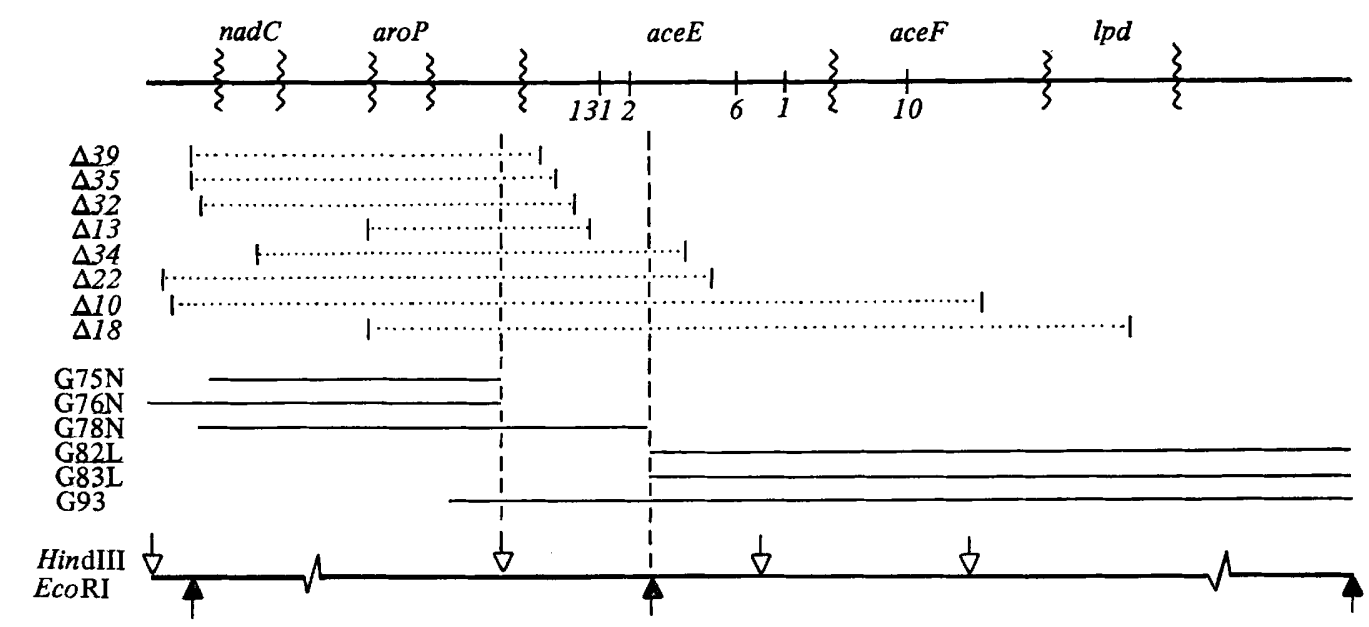

Fig. 6. Correlation of the physical and genetic maps in the ace region (not to scale). The positions of the fragments of bacterial DNA included in the transducing phages relative to the genetic map of the ace-lpd region of $E$. coli (Langley \& Guest, 1978) are based on the transduction frequencies obtained with ace point and deletion mutants (Table 4). The approximate positions of point mutations and deletion end-points are shown by vertical bars, the deleted regions are shown by dotted lines. The vertical zig-zag lines denote possible extremities of the corresponding structural genes. The data locate one target for R.HindIII very close to the operator proximal end of the ace $E$ gene and a target for R.EcoRI in the aceE gene between the aceE2 mutation and the end of deletion $\Delta 34$.

mutation and the end of deletion $\Delta 34$. The results are consistent with the marker order defined previously by P1-transduction (Langley \& Guest, 1978).

The segments of bacterial DNA contained by some of the transducing phages and the correlation between physical and genetic maps at two of the restriction targets are shown in Fig. 6.

\section{DISCUSSION}

Biochemical, genetic and physical evidence is presented for the incorporation of the genes coding for the pyruvate dehydrogenase complex of $E$. coli in $\lambda$ vectors. Consistent with the large size of the polypeptide components and the corresponding coding sequence (approximately $6.5 \mathrm{~kb}$ ), the genes were found to be distributed between two types of phages, $\lambda$ nadC and $\lambda l p d$. In fact, two large R.EcoRI fragments or at least three R.HindIII fragments, containing a common segment of $9.5 \mathrm{~kb}$, were needed to express a functional complex. The results suggest that the ace $E$ and $a c e F$ genes each contain a R.HindIII target. Thus, the ace $E$ gene should be encoded by the two small R.HindIII fragments $(2 \cdot 1$ and $2.0 \mathrm{~kb})$ with the ace $F$ gene spanning the $2.0 \mathrm{~kb}$ fragment and the $5.4 \mathrm{~kb}$ double-digestion product (Fig. 3 and 6). It is probable that the $5.4 \mathrm{~kb}$ fragment contains a functional lpd gene and up to $3.0 \mathrm{~kb}$ of unrelated DNA. The R.EcoRI fragment $(8 \cdot 2 \mathrm{~kb})$ cloned in the $\lambda l p d$ phages extended from a point in the aceE gene to a point beyond the lpd gene (Fig. 6). This fragment should contain an intact $a c e F$ gene that is presumably not expressed because it is a distal gene divorced from its promoter. Nevertheless, the $\lambda l p d$ phages might have been expected to generate Ace $^{+}$transduction plaques at a high frequency with ace $E^{+}$ace $F^{-}$ recipients (e.g. the aceF10 mutant) by expressing their $a c e F$ gene from a phage promoter and thus enabling all the components of a functional pyruvate dehydrogenase complex to be synthesized. The relatively low frequencies observed could indicate that successful expression of the $a c e F$ gene requires simultaneous transcription or translation of the proximal aceE gene. Alternatively, the frequencies of Ace transduction were equally low $(<0.002$ transductants per p.f.u.) with phages containing the entire aceE-aceF-lpd region so the results 
may be a direct consequence of the specific selection procedures employed. By contrast, the $l p d$ gene was cloned in the $\lambda l p d$ phages in a form that is expressible in the prophage state. This confirms that the lpd gene is not an obligatory component of the ace operon but an independent gene that can be transcribed from its own promoter. The direction of lpd transcription was not investigated but the existence of $\lambda l p d$ transducing phages with both orientations of the lpd gene should facilitate the identification of the coding strand.

The $n a d C$ and aroP genes were expressed by all of the $\lambda$ nadC phages and this places them in the $8.9 \mathrm{~kb}$ double-digestion product that is common to these transducing phages (Fig. 3 ). These genes would not be expected to occupy more than $3 \mathrm{~kb}$ so the cloned region contains an additional coding capacity equivalent to approximately $7.5 \mathrm{~kb}$ of DNA with unidentified functions. The azi and $m u t T$ genes appeared not to be included in the cloned region.

It is anticipated that the existence of transducing phages containing the genetic determinants for the pyruvate dehydrogenase complex will provide the basis for a speedy solution of many of the outstanding problems connected with the genetic organization and expression of the ace and $l p d$ genes as well as the primary structures and assembly of the gene products.

We would like to thank Noreen and Ken Murray for invaluable help and advice as well as providing recombinant phage lysates, restriction enzymes, and the facilities of the Department of Molecular Biology, Edinburgh University for part of this work. We also thank Pam Beattie for performing the electron microscopic heteroduplex analysis and Ruth Roberts for assistance with the enzymology. We are grateful to the Science Research Council for a project grant (J.R.G.) and a studentship (P.E.S.).

This paper is dedicated to the memory of Ian T. Creaghan.

\section{REFERENCES}

BACHMANN, B. J. \& Low, K. B. (1980). Linkage map of Escherichia coli K-12. Edition 6. Microbiological Reviews 44, 1-56.

Borck, K., Beggs, J. D., Brammar, W. J., Hopkins, A. S. \& Murray, N. E. (1976). The construction in vitro of transducing derivatives of phage lambda. Molecular and General Genetics 146, 199207.

Cole, S. T. \& Guest, J. R. (1980). Genetic and physical characterization of lambda transducing phages $(\lambda f r d A)$ containing the fumarate reductase gene of Escherichia coli K12. Molecular and General Genetics 178, 409-418.

Cox, E. C. \& Yanofsky, C. (1969). Mutator gene studies in Escherichia coli. Journal of Bacteriology 100, 390-397.

Danson, M. J., Hale, G., Johnson, P., Perham, R. N., SMITH, J. \& SPRAGG, P. (1979). Molecular weight and symmetry of the pyruvate dehydrogenase multienzyme complex of Escherichia coli. Journal of Molecular Biology 129, 603-617.

Davis, R. N., Simon, M. \& Davidson, N. (1971). Electron microscopic heteroduplex methods for mapping regions of base sequence homology in nucleic acids. Methods in Enzymology 21, 413-428.

Eley, M. H., Namihara, G., Hamilton, L., MUNK, P. \& REED, L. J. (1972). $\alpha$-Keto acid dehydrogenase complexes XVIII. Subunit composition of the Escherichia coli pyruvate dehydrogenase complex. Archives of Biochemistry and Biophysics 152, 655-669.

GebhardT, C., Mecke, D. \& Bisswanger, H. (1978). Dihydrolipoamide transacetylase from Escherichia coli: evidence for internal gene duplication.
Biochemical and Biophysical Research Communications 84, 508-514.

GUEST, J. R. (1974). Gene-protein relationships of the $\alpha$-keto acid dehydrogenase complexes of Escherichia coli K12: chromosomal location of the lipoamide dehydrogenase gene. Journal of General Microbiology 80, 523-532.

GUEST, J. R. (1978). Aspects of the molecular biology of lipoamide dehydrogenase. Advances in Neuro$\operatorname{logy} 21,219-244$.

Guest, J. R. \& Creaghan, I. T. (1973). Geneprotein relationships of the $\alpha$-keto acid dehydrogenase complexes of Escherichia coli K12: isolation and characterization of lipoamide dehydrogenase mutants. Journal of General Microbiology 75, 197-210.

Kaiser, A. D. \& Hogness, D. S. (1960). The transformation of $E$. coli with deoxyribonucleic acid isolated from bacteriophage lambda $\lambda \mathrm{dg}$. Journal of Molecular Biology 2, 392-415.

LANGLEY, D. \& Guest, J. R. (1977). Biochemical genetics of the $\alpha$-keto acid dehydrogenase complexes of Escherichia coli $\mathrm{K} 12$ : isolation and biochemical properties of deletion mutants. Journal of General Microbiology 99, 263-276.

LANGLeY, D. \& Guest, J. R. (1978). Biochemical genetics of the $\alpha$-keto acid dehydrogenase complexes of Escherichia coli K12: genetic characterization and regulatory properties of deletion mutants. Journal of General Microbiology 106, 103-117.

LENNOX, E. S. (1955). Transduction of linked genetic characters of the host by bacteriophage P1. Virology 1, 190-206. 
Murray, N. E., Brammar, W. J. \& Murray, K (1977). Lambdoid phages that simplify the recovery of in vitro recombinants. Molecular and General Genetics 150, 53-61.

REED, L. J. (1974). Multienzyme complexes. Accounts of Chemical Research 7, 40-46.

VoGEL, O. (1977). Redetermination of the molecular weights of the components of the pyruvate dehydrogenase complex from $E$. coli $\mathrm{K} 12^{+}$. Biochemical and Biophysical Research Communications 74, 1235-1241.

Vogel, O. \& Henning, U. (1971). Pyruvate dehydrogenase component subunit structure of the Escherichia coli $\mathrm{K} 12$ pyruvate dehydrogenase complex. European Journal of Biochemistry 18, 103-115.
Vogel, O., BeIKIRCh, H., MülleR, H. \& HeNNING, U. (1971). The subunit structure of the Escherichia coli $\mathrm{K}-12$ pyruvate dehydrogenase complex. The dihydrolipoamide transacetylase component. European Journal of Biochemistry 20, 169-178.

Yamamoto, K. R., Alberts, B. M., Benzinger, R., LAWHORNE, L. \& THEIBER, G. (1970). Rapid bacteriophage sedimentation in the presence of polyethyleneglycol and its application to largescale virus production. Virology 40, 734-744.

Zissler, J., Signer, E. \& Schaeffer, E. (1971). The role of recombination in growth of bacteriophage lambda $\mathrm{U}$. Inhibition of growth by prophage P2. In The Bacteriophage Lambda, pp. 469-475. Edited by A. D. Hershey. New York: Cold Spring Harbor Press. 